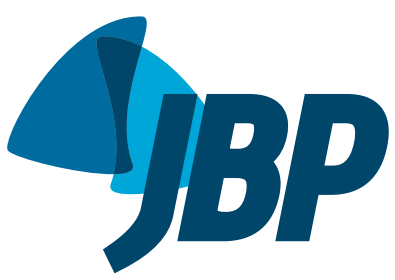

1. Divisão de Pneumologia, Instituto do Coração - InCor - Hospital das Clínicas, Faculdade de Medicina, Universidade de São Paulo, São Paulo (SP) Brasil.

2. Universidade Federal Fluminense, Niterói (RJ) Brasil.

3. Universidade Federal do Rio de Janeiro, Rio de Janeiro (RJ) Brasil.

4. Universidade Federal de Ciências da Saúde de Porto Alegre, Porto Alegre (RS) Brasil.

5. Santa Casa de Misericórdia de Porto Alegre, Porto Alegre (RS) Brasil.

6. Escola de Medicina. Pontifícia Universidade Católica do Rio Grande do Sul - PUCRS - Porto Alegre (RS) Brasil.

Submitted: 9 November 2016. Accepted: 26 February 2017.

Study carried out in the Divisão de Pneumologia, Instituto do Coração - InCor - Hospital das Clínicas, Faculdade de Medicina, Universidade de São Paulo, São Paulo (SP) Brasil.

\title{
Diffuse cystic lung diseases: differential diagnosis
}

\author{
Bruno Guedes Baldi', Carlos Roberto Ribeiro Carvalho', Olívia Meira Dias',
} Edson Marchiori ${ }^{2,3}$, Bruno Hochhegger ${ }^{4,5,6}$

\begin{abstract}
Diffuse cystic lung diseases are characterized by cysts in more than one lung lobe, the cysts originating from various mechanisms, including the expansion of the distal airspaces due to airway obstruction, necrosis of the airway walls, and parenchymal destruction. The progression of these diseases is variable. One essential tool in the evaluation of these diseases is HRCT, because it improves the characterization of pulmonary cysts (including their distribution, size, and length) and the evaluation of the regularity of the cyst wall, as well as the identification of associated pulmonary and extrapulmonary lesions. When combined with clinical and laboratory findings, HRCT is often sufficient for the etiological definition of diffuse lung cysts, avoiding the need for lung biopsy. The differential diagnoses of diffuse cystic lung diseases are myriad, including neoplastic, inflammatory, and infectious etiologies. Pulmonary Langerhans cell histiocytosis, lymphangioleiomyomatosis, lymphocytic interstitial pneumonia, and follicular bronchiolitis are the most common diseases that produce this CT pattern. However, new diseases have been included as potential determinants of this pattern.
\end{abstract}

Keywords: Cysts; Diagnosis, differential; Lung diseases, interstitial; Tomography, X-ray computed.

\section{INTRODUCTION}

A cyst is defined as a round circumscribed area that is surrounded by an epithelial or fibrous wall of variable thickness. On chest $\mathrm{CT}$, a cyst is seen as an area with a low attenuation coefficient in the lung parenchyma, having a well-defined interface with the adjacent normal lung and usually containing air, although it can occasionally have a liquid or solid content. ${ }^{(1)}$ A lung cyst can originate from various mechanisms, such as airway obstruction with distal airspace dilatation (check-valve mechanism), necrosis of the airway walls, and lung parenchymal destruction by proteases. ${ }^{(2)}$ Diffuse cystic lung diseases are characterized by cysts in more than one lung lobe, the cysts usually being bilateral.

HRCT has broadened the understanding of diffuse cystic lung diseases, because it enables improved identification of cyst characteristics (including their distribution) and associated lesions (including assessment of the presence of extrapulmonary changes), narrowing the differential diagnosis and often avoiding the need for diagnostic confirmation by lung biopsy. ${ }^{(3)}$

The differential diagnoses of diffuse cystic lung diseases are myriad, including neoplastic, inflammatory, and infectious diseases, which have variable prognoses. Recently, other potential etiologies of this CT pattern have been proposed including constrictive bronchiolitis and paracoccidioidomycosis. ${ }^{(4,5)}$
The objective of the present pictorial essay was to describe the main diseases that can lead to the formation of diffuse cysts in the lung parenchyma, with an emphasis on CT findings (Table 1 ).

\section{PULMONARY LANGERHANS CELL HISTIOCYTOSIS}

Pulmonary Langerhans cell histiocytosis (PLCH) is characterized by the infiltration of Langerhans cells mainly in the lungs and less commonly in other organs, leading to the activation of an inflammatory process with potential dysfunction in the affected sites. It remains controversial whether PLCH is a polyclonal neoplastic or inflammatory disease. The mean age of patients ranges from 20 to 40 years, and, in more than $90 \%$ of cases, the disease is associated with a current or previous smoking history, including passive smoking. The lung is the most commonly involved site, and the most common symptom is progressive dyspnea on exertion; however, patients can be asymptomatic. There can be fever, sweating, weight loss, and, less commonly, extrapulmonary manifestations, such as diabetes insipidus, and bone and skin lesions. ${ }^{(6)}$

The initial HRCT findings of PLCH are centrilobular or peribronchiolar nodules, which usually measure $1-10 \mathrm{~mm}$ in diameter and are irregularly marginated. As the disease progresses, the nodules undergo cavitation and produce cystic lesions. A combination of nodules and cysts is often 
Table 1. Major etiologies of diffuse lung cysts.

\begin{tabular}{|c|c|c|}
\hline Disease & $\begin{array}{l}\text { Lung cyst distribution and } \\
\text { characteristics }\end{array}$ & Other possible radiological findings \\
\hline $\begin{array}{l}\text { Pulmonary Langerhans cell } \\
\text { histiocytosis }\end{array}$ & $\begin{array}{l}\text { - Cysts are irregular and thick- or } \\
\text { thin-walled, later becoming bizarre } \\
\text { in shape, and can coalesce } \\
\text { - Vary in number and size } \\
\text { - Predominate in the upper lung } \\
\text { zones, sparing the region of the } \\
\text { costophrenic sinuses }\end{array}$ & $\begin{array}{l}\text { - Irregularly marginated centrilobular or } \\
\text { peribronchiolar nodules measuring } 1-10 \mathrm{~mm} \text { in } \\
\text { diameter } \\
\text { - Enlargement of the pulmonary trunk and of } \\
\text { the right and left pulmonary arteries }\end{array}$ \\
\hline Lymphangioleiomyomatosis & $\begin{array}{l}\text { - Cysts are regular and thin-walled } \\
\text { and usually measure } 2-10 \mathrm{~mm} \text { in } \\
\text { diameter } \\
\text { - Are diffusely distributed } \\
\text { - Vary in number }\end{array}$ & $\begin{array}{l}\text { - Small regular centrilobular nodules } \\
\text { - Areas of ground-glass opacity } \\
\text { - Pleural effusion } \\
\text { - Ascites } \\
\text { - Renal angiomyolipoma } \\
\text { - Abdominal and pelvic lymphangioleiomyomas }\end{array}$ \\
\hline $\begin{array}{l}\text { Lymphocytic interstitial } \\
\text { pneumonia }\end{array}$ & $\begin{array}{l}\text { - Cysts vary in shape and are thin- } \\
\text { walled } \\
\text { - Measure up to } 30 \mathrm{~mm} \text { in diameter } \\
\text { - Are diffusely distributed, } \\
\text { predominating in the lower lobes and } \\
\text { along the peribronchovascular bundle }\end{array}$ & $\begin{array}{l}\text { - Ground-glass opacities and focal } \\
\text { consolidations } \\
\text { - Peribronchovascular bundle thickening } \\
\text { - Poorly defined centrilobular nodules } \\
\text { - Interlobular septal thickening } \\
\text { - Reticular opacities } \\
\text { - Mediastinal and hilar lymph node } \\
\text { enlargement }\end{array}$ \\
\hline Follicular bronchiolitis & $\begin{array}{l}\text { - Cysts vary in shape and are thin- } \\
\text { walled } \\
\text { - Measure up to } 30 \mathrm{~mm} \text { in diameter } \\
\text { - Are diffusely distributed, } \\
\text { predominating in the lower lobes and } \\
\text { along the peribronchovascular bundle }\end{array}$ & $\begin{array}{l}\text { - Centrilobular nodules or ground-glass } \\
\text { opacities }\end{array}$ \\
\hline Birt-Hogg-Dubé syndrome & $\begin{array}{l}\text { - Cysts are multiple and irregular } \\
\text { - Predominate in the lower medial } \\
\text { and subpleural regions of the lung }\end{array}$ & \\
\hline $\begin{array}{l}\text { Light-chain deposition } \\
\text { disease }\end{array}$ & $\begin{array}{l}\text { - Cysts are diffuse and thin-walled, } \\
\text { without a predominant distribution } \\
\text { - Measure up to } 20 \mathrm{~mm} \text { in diameter. }\end{array}$ & $\begin{array}{l}\text { - Nodules } \\
\text { - Mediastinal lymph node enlargement }\end{array}$ \\
\hline Amyloidosis & $\begin{array}{l}\text { - Cysts are thin-walled } \\
\text { - Vary in size } \\
\text { - Predominate peripherally }\end{array}$ & $\begin{array}{l}\text { - Nodules or masses } \\
\text { - Interlobular septal thickening } \\
\text { - Ground-glass opacities } \\
\text { - Lymph node enlargement }\end{array}$ \\
\hline $\begin{array}{l}\text { Cystic pulmonary metastatic } \\
\text { disease }\end{array}$ & $\begin{array}{l}\text { - Cysts are diffuse } \\
\text { - Are thick- or thin-walled }\end{array}$ & - Nodules or masses \\
\hline Paracoccidioidomycosis & $\begin{array}{l}\text { - Cysts are diffuse and thin-walled, } \\
\text { without a predominant distribution } \\
\text { - Are few in number }\end{array}$ & $\begin{array}{l}\text { - Reticular and linear opacities, consolidations, } \\
\text { areas of "reversed halo" sign, bronchiectasis, } \\
\text { and cavitated lesions } \\
\text { - Paracicatricial emphysema }\end{array}$ \\
\hline Pneumocystosis & $\begin{array}{l}\text { - Cysts vary in size, shape, and wall } \\
\text { thickness } \\
\text { - Predominate in the upper lobes }\end{array}$ & $\begin{array}{l}\text { - Extensive areas of ground-glass opacity, } \\
\text { predominating in the central and perihilar } \\
\text { regions } \\
\text { - Septal thickening }\end{array}$ \\
\hline $\begin{array}{l}\text { Infection with Staphylococcus } \\
\text { aureus }\end{array}$ & - Pneumatoceles & \\
\hline Constrictive bronchiolitis & $\begin{array}{l}\text { - Cysts are thin-walled } \\
\text { - Are few in number and randomly } \\
\text { distributed }\end{array}$ & $\begin{array}{l}\text { - Areas of mosaic attenuation } \\
\text { - Bronchiectasis and bronchiolectasis } \\
\text { - Bronchial wall thickening }\end{array}$ \\
\hline Hypersensitivity pneumonitis & $\begin{array}{l}\text { - Cysts are sparse, few in number, } \\
\text { and randomly distributed }\end{array}$ & $\begin{array}{l}\text { - Centrilobular ground-glass micronodules } \\
\text { - Areas of mosaic attenuation } \\
\text { - Usual interstitial pneumonia or nonspecific } \\
\text { interstitial pneumonia pattern }\end{array}$ \\
\hline $\begin{array}{l}\text { Desquamative interstitial } \\
\text { pneumonia }\end{array}$ & $\begin{array}{l}\text { - Cysts are regular and measure up to } \\
20 \mathrm{~mm} \text { in diameter } \\
\text { - Predominate in the lower lung zones }\end{array}$ & $\begin{array}{l}\text { - Diffuse ground-glass opacities predominating } \\
\text { in the lower lung zones } \\
\text { - Mild distortion of the lung architecture }\end{array}$ \\
\hline
\end{tabular}


observed (Figure 1A), which is sufficient for diagnostic confirmation. In later stages of the disease, cysts predominate, vary in number and size, are irregular and often bizarre-shaped, and can coalesce (Figure 1B). Initially, the walls of the cysts are thick, and, later, they become thinner. Cystic lesions predominate in the upper lobes, sparing the region of the costophrenic sinuses (Figure 1C). Pneumothorax can occur in up to $15 \%$ of cases (Figure 1D). ${ }^{(3,6)}$ It is speculated that the cysts are formed by airway dilatation due to bronchiolar wall inflammation, nodule cavitation, or air space enlargement secondary to traction from fibrosing lesions. CT changes secondary to pulmonary hypertension, such as enlargement of the pulmonary trunk and of the right and left pulmonary arteries, can also be identified. ${ }^{(3)}$

The diagnosis of PLCH is confirmed when young individuals who are smokers present with a combination of nodules and cysts in the upper lung zones, sparing the region of the costophrenic sinuses. In cases of cysts without nodules, the diagnosis can be confirmed by bronchoscopy, despite its low sensitivity, when more than $5 \%$ of CD1a-positive cells are identified in the bronchoalveolar lavage fluid, or by transbronchial biopsy. In this context, surgical lung biopsy provides a higher diagnostic yield. Biopsy of skin or bone lesions can also establish the diagnosis of $\mathrm{PLCH} .{ }^{(6)}$

\section{LYMPHANGIOLEIOMYOMATOSIS}

Lymphangioleiomyomatosis (LAM) is a low-grade neoplasm that most commonly affects women of reproductive age; LAM is characterized by a proliferation of atypical smooth muscle cells (LAM cells) around the airways, blood vessels, and lymphatic vessels; LAM occurs as an isolated disorder or in association with tuberous sclerosis complex, being caused by mutations in the tuberous sclerosis complex 1 or 2 genes. ${ }^{(7,8)}$ The most common respiratory manifestations of LAM include progressive dyspnea on exertion and recurrent pneumothorax (in up to $70 \%$ of cases) and, less commonly, cough, hemoptysis, and chylothorax. (8) Cysts in LAM are usually regular and thin-walled; typically measure 2-10 $\mathrm{mm}$ in diameter, are diffusely distributed, and vary in number; and are surrounded by normal lung parenchyma (Figures $2 \mathrm{~A}$ and $2 \mathrm{~B}$ ). ${ }^{(9)}$ Cyst formation in LAM is hypothesized to result from obstruction of terminal bronchioles by LAM cells with distal airspace dilatation and/or from degradation of the lung parenchyma due to an imbalance between proteases and protease inhibitors. ${ }^{(3,9)}$ On CT, other changes can be found, such as pneumothorax, renal angiomyolipoma, chylothorax, chylous ascites, and abdominal and pelvic lymphangioleiomyomas (Figures $2 \mathrm{C}$ and 2D). In addition, there can be regular centrilobular nodules, usually due to multifocal micronodular pneumocyte hyperplasia and, less commonly, due to areas of ground-glass opacity secondary to alveolar hemorrhage or lymphatic congestion. $(3,9)$

The diagnosis of LAM can be confirmed by an HRCT finding of cysts characteristic of LAM, in association with the presence of at least one of the following clinical manifestations: tuberous sclerosis complex;

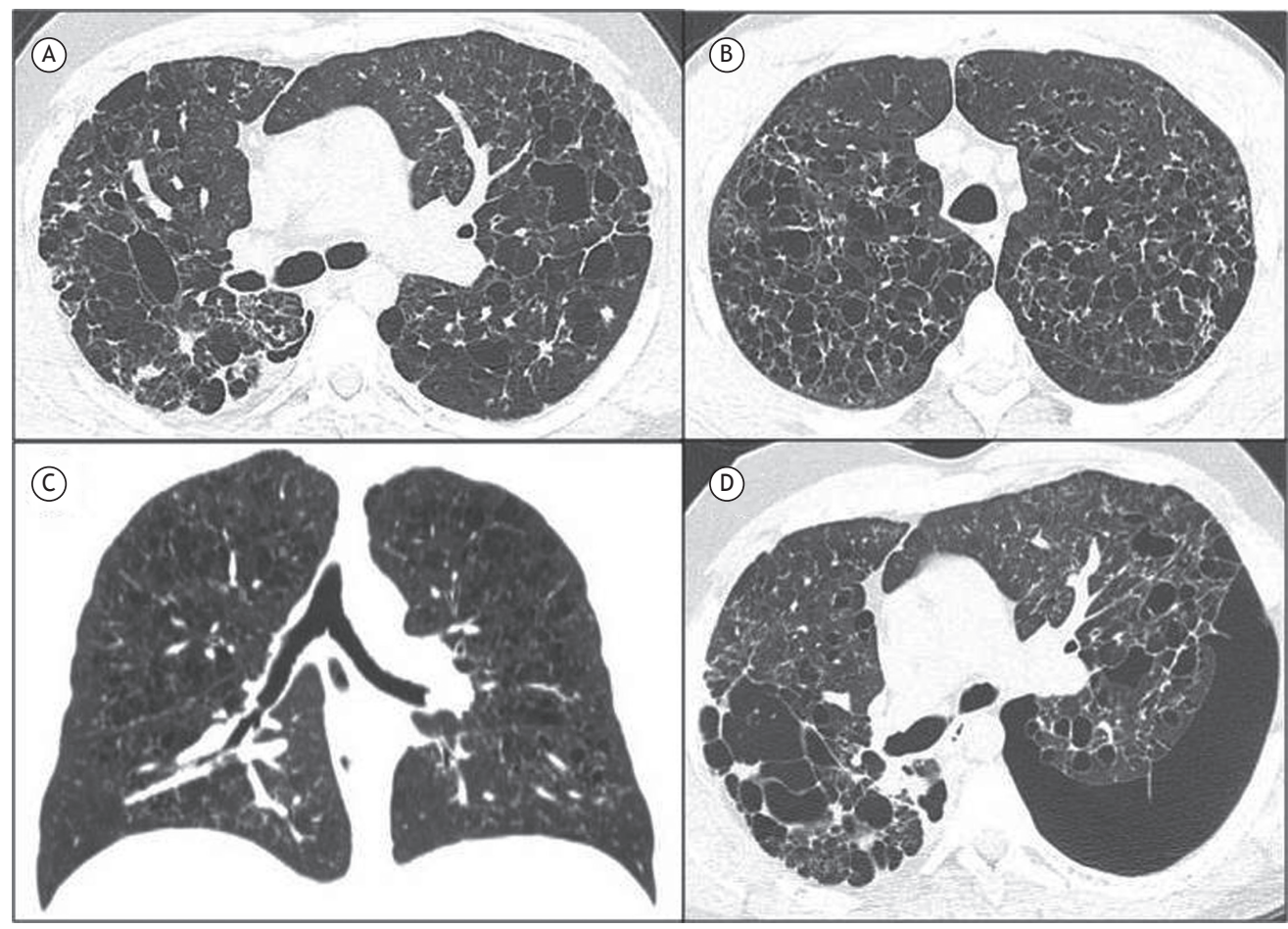

Figure 1. CT scans of patients with pulmonary Langerhans cell histiocytosis. In A, irregular cysts and irregularly marginated centrilobular nodules in the upper lobes (axial reconstruction). In B, irregular thin-walled cysts (axial reconstruction). In $C$, irregular cysts predominating in the upper lobes and sparing the region of the costophrenic sinuses (coronal reconstruction). In $\mathrm{D}$, irregular cysts, some centrilobular nodules, and a left pneumothorax (axial reconstruction). 
renal angiomyolipoma; lymphangioleiomyoma; chylothorax; or chylous ascites. However, if one of the characteristics described above is missing, the diagnosis can be established by the identification of an increase in serum VEGF-D levels, especially if these levels are above $800 \mathrm{pg} / \mathrm{mL}$. If quantification of serum VEGF-D levels is not available or if serum VEGF-D levels are not increased, it is recommended that lung biopsy (preferably surgical) be performed. ${ }^{(7)}$

\section{LYMPHOCYTIC INTERSTITIAL PNEUMONIA}

Lymphocytic interstitial pneumonia (LIP) is a rare, benign, lymphoproliferative disease characterized histologically by a lymphocytic and plasmacytic infiltrate that affects alveoli and interlobular septa and can possibly form nodular lymphoid aggregates with reactive germinal centers. ${ }^{(10)}$ The incidence of LIP is higher in women, usually between the fourth and sixth decades of life. LIP is usually associated with other systemic diseases, especially connective tissue diseases, such as Sjögren's syndrome and systemic lupus erythematosus; HIV infection; Epstein-Barr virus infection; and acquired immunodeficiencies, such as common variable immunodeficiency. The idiopathic form of LIP is rare. Patients can be asymptomatic, and the major clinical manifestations of LIP include dyspnea, cough, fatigue, and chest pain. ${ }^{(10,11)}$ The most commonly observed pattern on pulmonary function testing is a restrictive pattern. ${ }^{(3)}$

Cysts are common in LIP, being present in up to 2 thirds of patients, and it is speculated that they result from ischemia due to vascular obstruction, postobstructive alveolar dilatation, or compression of bronchioles by lymphoid tissue, leading to a check-valve mechanism. (2) The cysts usually measure up to 30 $\mathrm{mm}$ in diameter, are thin-walled, vary in shape, and are diffusely distributed, predominating in the lower lobes and along the peribronchovascular bundle (Figure 3). Other CT changes that aid in the diagnosis of LIP include ground-glass opacities and focal consolidations, peribronchovascular bundle thickening, and poorly defined centrilobular nodules. Less commonly, interlobular septal thickening, reticular opacities, pleural thickening due to subpleural nodules, and mediastinal/ hilar lymph node enlargement can be found. (2) In the absence of a clearly diagnosed systemic disease, it is

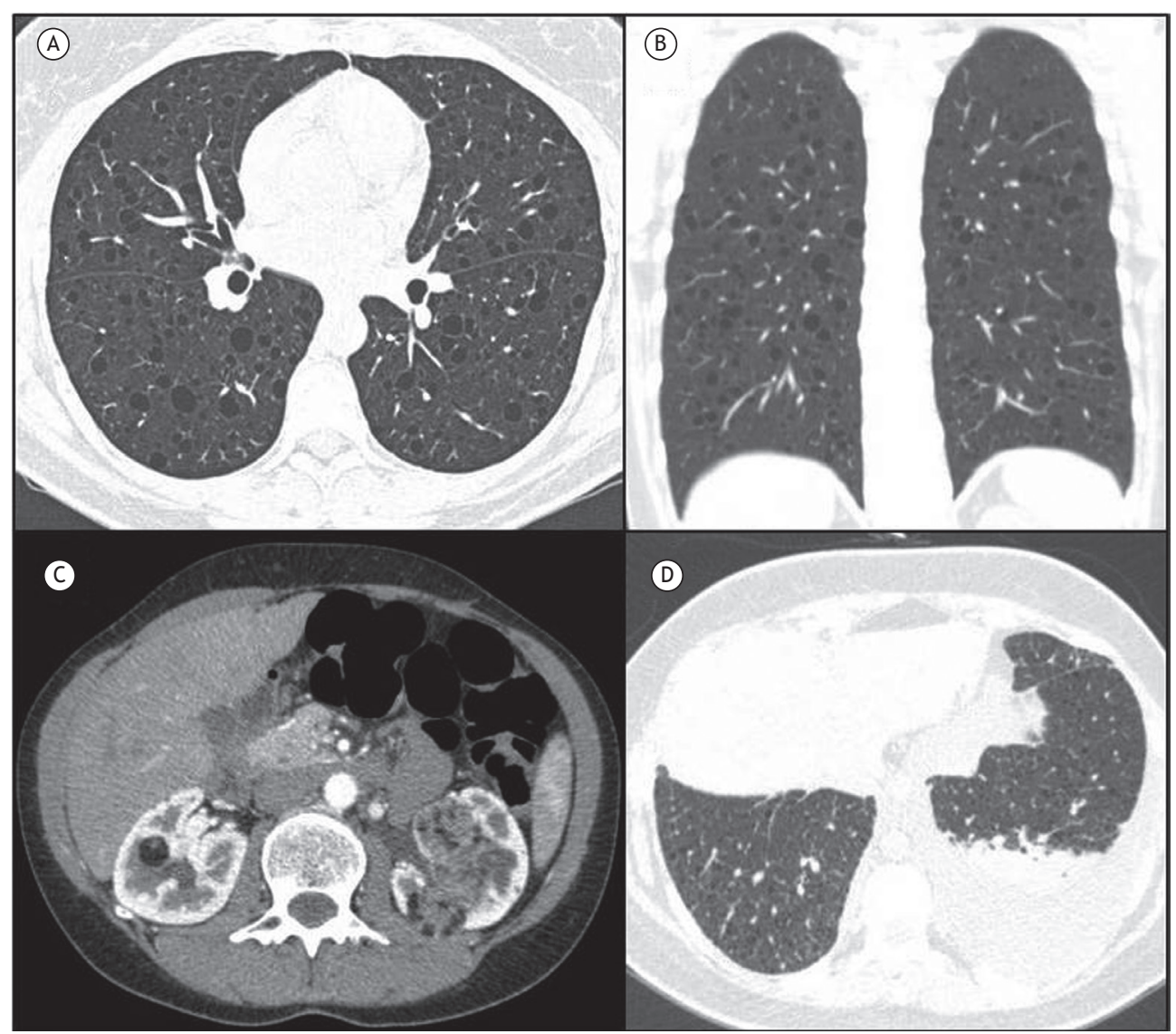

Figure 2. In A, axial reconstruction and, in B, coronal reconstruction of chest CT scans of a female patient with lymphangioleiomyomatosis, showing diffuse lung cysts with regular walls. In C, axial reconstruction of an abdominal CT scan of a female patient with lymphangioleiomyomatosis, showing bilateral, heterogeneous renal masses, consistent with angiomyolipoma. In D, axial reconstruction of a CT scan of a female patient with lymphangioleiomyomatosis, showing diffuse lung cysts and a left chylothorax. 
recommended that the diagnosis of LIP be confirmed histologically. ${ }^{(11)}$

\section{FOLLICULAR BRONCHIOLITIS}

Follicular bronchiolitis is also part of the spectrum of lymphoproliferative disorders with lung involvement-the main finding that differentiates it from LIP is bronchiolocentric lymphocytic infiltration, which does not extend into other lung interstitial compartments; in addition, an obstructive pattern with air trapping is the most common pattern in follicular bronchiolitis. ${ }^{(11)}$ The major mechanism responsible for cyst formation involves extrinsic compression of the bronchus-associated lymphoid tissue, causing a check-valve phenomenon, but it may also be related to bronchiolar ischemia due to vascular obstruction. The cysts are similar to those found in LIP, being predominantly peribronchovascular in distribution and thin-walled (Figure 4). There can be centrilobular nodules or ground-glass opacities. ${ }^{(2)}$

\section{BIRT-HOGG-DUBÉ SYNDROME}

Birt-Hogg-Dubé syndrome (BHDS) is a rare autosomal dominant disorder characterized by the development of follicular tumors, renal tumors, and lung cysts. BHDS is caused by heterozygous mutations in the gene encoding folliculin (FLCN) and located on chromosome 17, which encodes a tumor suppressor protein. Although treatment of renal tumors of low malignant potential is the primary focus of longitudinal care, pulmonary manifestations, especially cyst formation and spontaneous pneumothorax, are common.

Lung cysts develop in adults around the age of 30-40 years; however, lung cysts have been described in patients between 20 and 85 years of age and occur with nearly complete penetrance in BHDS. ${ }^{(12,13)}$ Toro et al. identified that $89 \%$ of 198 patients with BHDS had lung cysts. ${ }^{(12)}$ Lung cysts in BHDS are multiple, irregular, and thin-walled; predominate in lower medial and subpleural regions of the lung; and are often

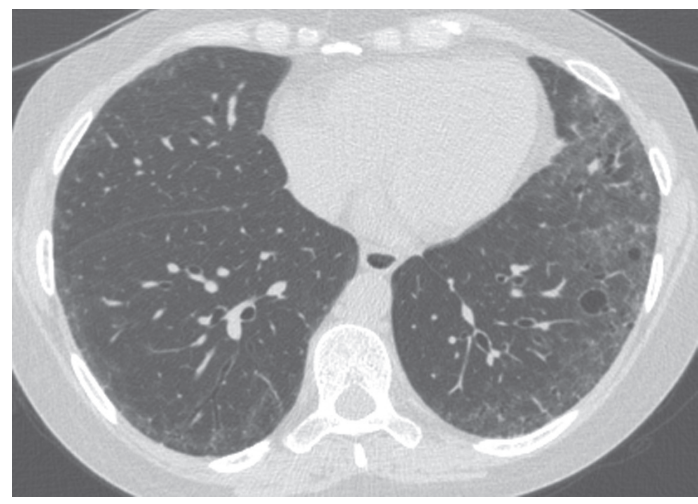

Figure 3. Axial reconstruction of a chest CT scan demonstrating lymphocytic interstitial pneumonia in a female patient with Sjögren's syndrome. Note the areas of ground-glass opacity, the reticular pattern, and the cysts predominating in the lower lung fields. mislabeled as bullae (Figure 5). A family history of pneumothorax is present in $35 \%$ of cases. ${ }^{(12,13)}$

The diagnosis of BHDS should be suspected in young patients presenting with spontaneous pneumothorax, especially those with a personal or family history of pneumothorax, skin lesions, or renal tumors. Menko et al. ${ }^{(14)}$ described criteria for the diagnosis of BHDS. These criteria are divided into major and minor criteria. The major criteria include: (1) at least five fibrofolliculomas or trichodiscomas, at least one of which being histologically confirmed, of adult onset; and (2) pathogenic FLCN germline mutation. The minor criteria include: (1) multiple bilateral lung cysts, with no other apparent cause, with or without spontaneous pneumothorax; (2) early-onset ( $<50$ years) renal cancer, multifocal or bilateral renal cancer, or chromophobe renal cell carcinoma (mixed variant) and oncocytic cell histology; and (3) a first-degree relative with BHDS. The diagnosis of BHDS requires the presence of one major criterion or two minor criteria.

\section{LIGHT-CHAIN DEPOSITION DISEASE}

Non-amyloid light-chain deposition disease (LCDD) is characterized by monoclonal protein deposition in several tissues and organs. Unlike in amyloidosis, these deposits do not stain with Congo red and are seen electron microscopically as amorphous nodular deposits. Renal involvement, determined by proteinuria and renal failure, is the most common manifestation, followed by cardiac and hepatic involvement. Of all cases of LCDD, $75 \%$ occur in association with multiple myeloma or macroglobulinemia.

Light chains are secreted by plasmocytes and are deposited in the alveolar walls, small airways, and vessels. The most common CT findings include nodules, lymph node enlargement, and diffuse thin-walled cysts measuring up to $2 \mathrm{~cm}$ in diameter (Figure 6). Cysts are

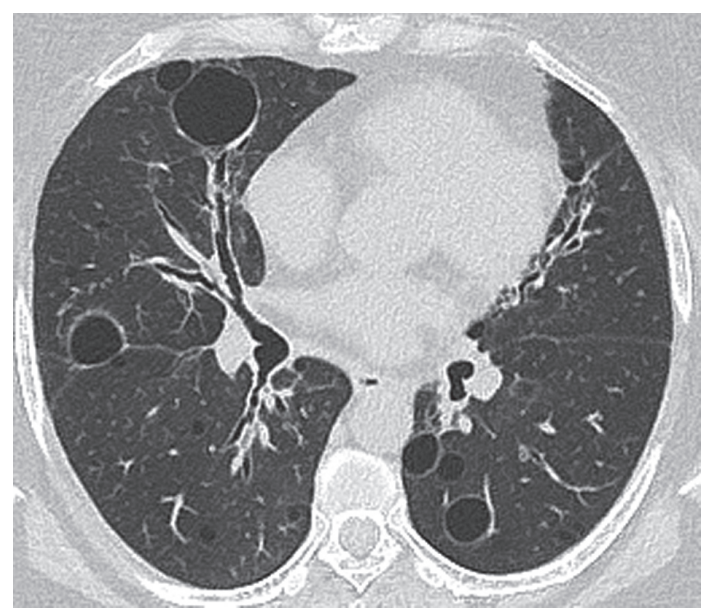

Figure 4. Axial reconstruction of a CT scan of a female patient with follicular bronchiolitis. Note the thinwalled cysts of various diameters throughout the lung parenchyma, especially along the peribronchovascular bundle. 


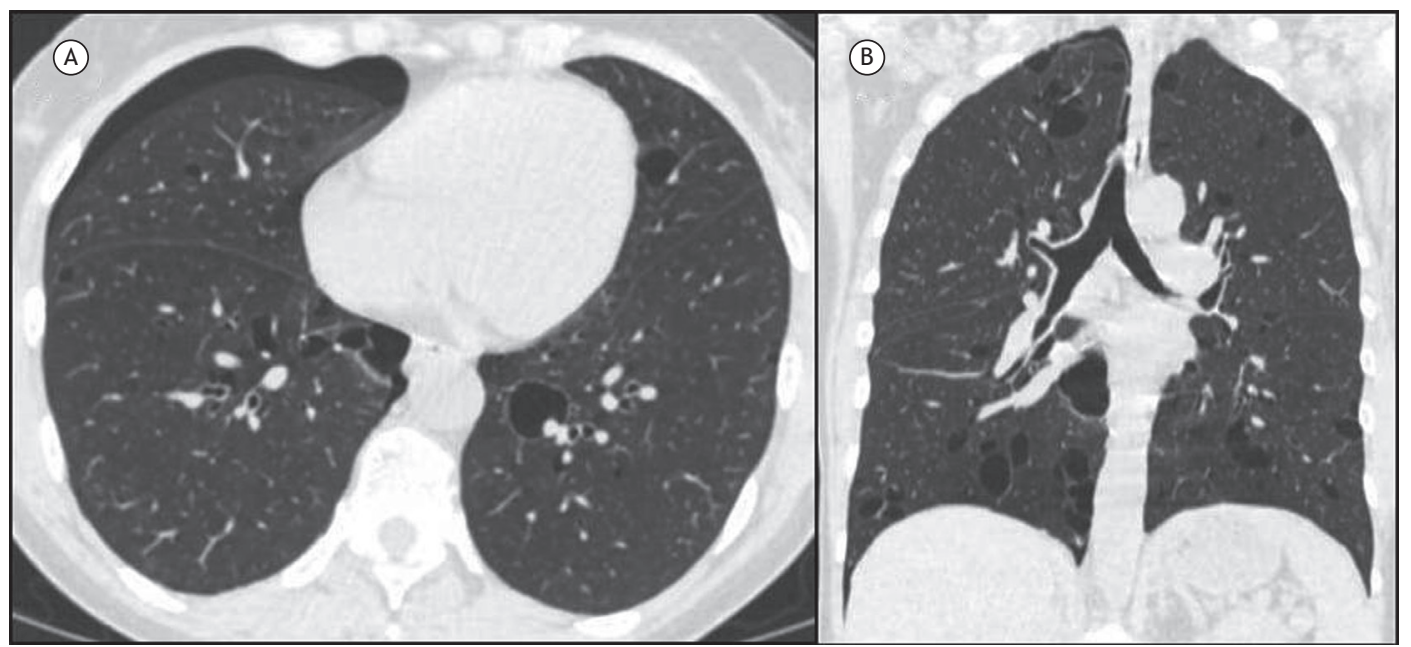

Figure 5. In A, axial reconstruction of a CT scan demonstrating thin-walled lung cysts and a right pneumothorax. In $B$, coronal reconstruction of a CT scan showing the distribution of the cysts in the lower lobes, a predominantly medial distribution. The patient in question was a 49-year-old female, had sudden dyspnea, and was diagnosed with BirtHogg-Dubé syndrome. The diagnosis was confirmed by the presence of characteristic lung cysts and a spontaneous pneumothorax and by a history of a first-degree relative with the disease.

believed to form as a result of small airway dilatation due to parietal deposits of protein.(15)

\section{AMYLOIDOSIS}

Amyloidosis is due to deposition of soluble plasma proteins within the extracellular space in an abnormal insoluble fibrillar form. The clinical manifestations and prognosis of amyloid deposits depend on their etiology and anatomical distribution. Amyloidosis is extremely heterogeneous and can be benign or potentially fatal, being classified as primary (i.e., associated with multiple myeloma or macroglobulinemia) or secondary (i.e., associated with rheumatoid arthritis, tuberculosis, Crohn's disease, cystic fibrosis, or Mediterranean fever).

CT findings of pulmonary amyloidosis include nodules, interlobular septal thickening, ground-glass opacities, and lymph node enlargement. Lung cysts are rare and are most often described with localized amyloidosis in association with Sjögren's syndrome. Proposed mechanisms of cyst formation include narrowing of the airway due to inflammatory cells, leading to a check-valve mechanism, and disruption of fragile alveolar walls due to amyloid deposition or due to ischemia from vascular infiltration by amyloid. The cysts are thin-walled, are predominantly peripheral, and are often accompanied by nodules or masses (Figure 7). The diagnosis of amyloidosis is based on histological confirmation through Congo red staining, which produces a greenish birefringence under cross-polarized light. ${ }^{(16,17)}$

\section{CYSTIC PULMONARY METASTATIC DISEASE}

Cystic pulmonary metastases occur most often in tumors of epithelial origin. The frequency of cavitation in metastatic nodules detected on X-ray is approximately
$4 \% .{ }^{(18)}$ Squamous cell carcinomas, especially of the head and neck (Figure 8), are the ones that most commonly lead to cavitated pulmonary metastases on X-ray (69\% of cases). ${ }^{(18,19)}$ However, cavitation in metastatic adenocarcinomas is also often found. ${ }^{(18-20)}$ Metastatic sarcomas and benign metastatic leiomyomas can also cause cavitation, and pneumothorax can be a complication. There can be nodules and masses. It should be borne in mind that chemotherapy can induce cavitation. The mechanism of cavitation is believed to be tumor necrosis or distal airspace dilatation secondary to bronchial infiltration by the tumor. Cavitated nodules with a thick wall are the most common, although cysts can be found especially in metastases from sarcomas and adenocarcinomas, as well as in benign metastatic leiomyoma. ${ }^{(20)}$

\section{INFECTIONS}

\section{Paracoccidioidomycosis}

Paracoccidioidomycosis, which is caused by the dimorphic fungus Paracoccidioides brasiliensis, is the most common systemic mycosis in Latin America. It predominates in males and in rural workers. Paracoccidioidomycosis is acquired by inhalation of infectious fungal particles that, upon reaching the lungs, cause the primary infection. Mucocutaneous lesions and lymph node enlargement are also common findings, and other less commonly affected organs include the kidneys, liver, bones, adrenal glands, central nervous system, and airways, with the formation of epithelioid granulomas, abscesses, and necrosis. ${ }^{(21)}$

Several radiological patterns have been described, including reticular opacities, consolidations, areas of "reversed halo" sign, bronchiectasis, pulmonary cavitations, and paracicatricial emphysema. ${ }^{(22)}$ In a CT review of 50 cases, ${ }^{(4)}$ lung cysts were found in $10 \%$ 


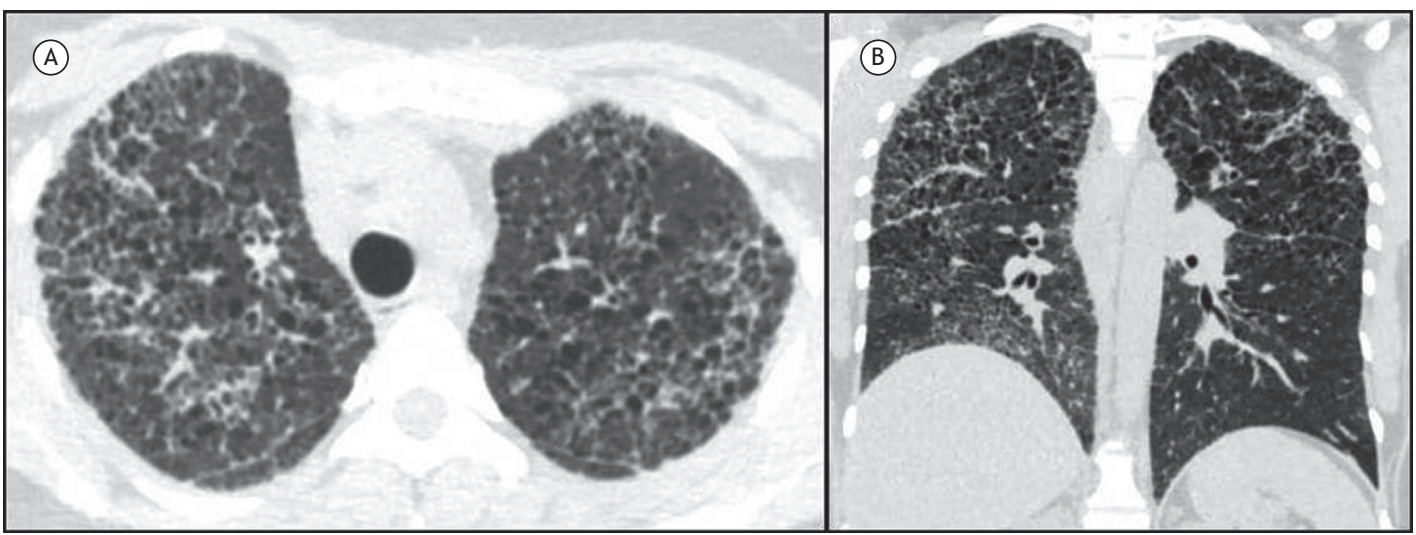

Figure 6. Chest CT scans. In A, axial reconstruction demonstrating several thin-walled, cystic structures associated with interlobular septal thickening and pulmonary micronodules. In B, coronal reconstruction showing the cranial distribution of the lung cysts. The patient in question was a 38-year-old female and was diagnosed with multiple myeloma, renal failure, and lung involvement associated with light-chain deposition disease.

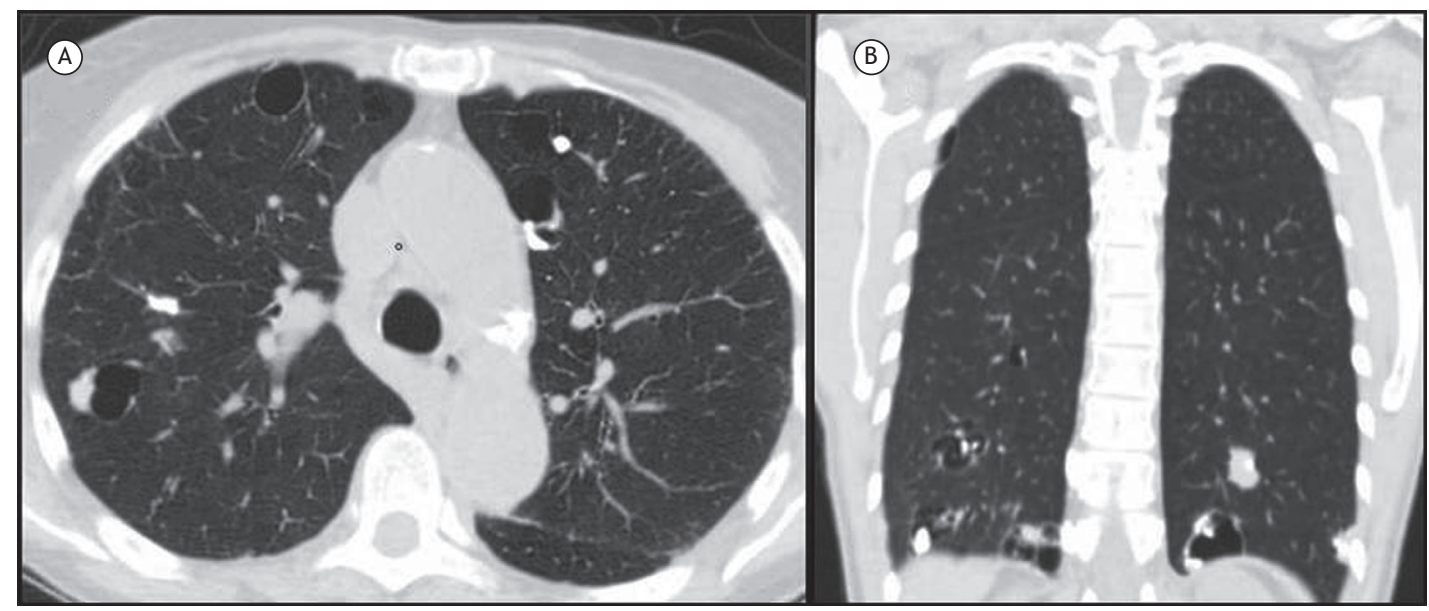

Figure 7. In $A$, axial reconstruction of a CT scan demonstrating several thin-walled, cystic structures associated with adjacent nodules, some of which were calcified. In B, coronal reconstruction of a CT scan showing randomly distributed lung cysts and associated nodules. The patient in question was a 56-year-old female and was diagnosed with Sjögren's syndrome and amyloidosis-related lung involvement.

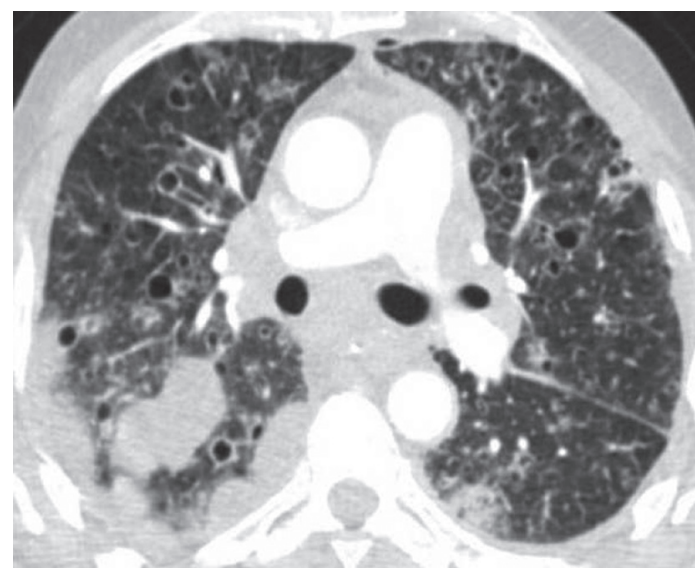

Figure 8. Axial reconstruction of a CT scan of a 66-yearold male patient with laryngeal squamous neoplasia. The scan demonstrates several cavitated nodules with a thick wall and cysts associated with loculated pleural effusion, also etiologically secondary to neoplasia. of cases, and, in most cases, the cysts were diffuse and thin-walled, showing no preferential distribution, and few in number. Postulated mechanisms of cyst formation include bronchial obstruction caused by centrilobular fibrosis, peribronchial granuloma formation leading to airway dilatation or central necrosis and lesion elastic recoil. ${ }^{(4)}$

\section{Pneumocystosis}

Pneumocystosis, which is caused by the fungus Pneumocystis jiroveci, occurs in immunocompromised patients, such as HIV-infected patients with CD4 lymphocyte counts below 200 cells $/ \mathrm{mm}^{3}$, bone marrow transplant recipients, and patients on immunosuppressants. Symptoms, such as nonproductive cough, low fever, and dyspnea, are insidious, and spontaneous pneumothorax can occur-if left untreated, patients can progress to respiratory failure and death. Lymphopenia and high serum levels of lactate dehydrogenase aid in the diagnosis. ${ }^{(23)}$ 
CT findings include extensive areas of ground-glass opacity, preferentially located in the central and perihilar regions; septal thickening; and, possibly, pleural effusion and lymph node enlargement. Intralobular septal thickening associated with ground-glass opacities can result in a "crazy-paving" pattern. Cysts are relatively common, especially in HIV-infected patients, varying in size, shape, and wall thickness and tending to have a predilection for the upper lobes (Figure 9). $(24,25)$ Cyst rupture can cause pneumothorax and pneumomediastinum. ${ }^{(24)}$

\section{Infection with Staphylococcus aureus}

Staphylococcal pneumonias can lead to the formation of pneumatoceles, which consist of gaseous airspaces resulting from airway dilatation due to a check-valve mechanism and occurring secondary to inflammation and parenchymal necrosis. ${ }^{(1)}$ Pneumatoceles are most common in patients under one year of age and in intravenous drug users, and lesions can resolve with treatment of the infection. ${ }^{(1,26)}$

\section{CONSTRICTIVE BRONCHIOLITIS}

Constrictive bronchiolitis consists of bronchiolar narrowing due to fibrosis. Its most common etiologies are viral infections; autoimmune diseases, such as rheumatoid arthritis; and graft-vs.-host disease after solid organ or bone marrow transplant. The most common symptoms of constrictive bronchiolitis are progressive dyspnea on exertion and dry cough, and, functionally, it is characterized by an obstructive pattern and air trapping. ${ }^{(27)}$

On HRCT, the most common changes of constrictive bronchiolitis include areas of mosaic attenuation, bronchiolectasis, bronchiectasis, and bronchial wall thickening. Cysts are rare, few in number, thin-walled, and randomly distributed. A check-valve mechanism due to airway obstruction, with air trapping and distal airspace dilatation, has been suggested as a factor in cyst formation in this condition. ${ }^{(5)}$

\section{HYPERSENSITIVITY PNEUMONITIS}

Hypersensitivity pneumonitis (HP) is an interstitial disease with variable clinical presentation, characterized by inflammation of the lung parenchyma secondary to inhalation of specific organic antigens, such as fungus and birds derivatives, or chemical substances, such as isocyanate. Progressive dyspnea and dry cough are the most common symptoms. Histologically, the subacute and chronic forms are characterized mainly by bronchiolocentric interstitial inflammation and poorly formed granulomas; in addition, there can be fibrosing forms, including the usual interstitial pneumonia pattern and nonspecific interstitial pneumonia. ${ }^{(28)}$

An HRCT finding of cysts in HP is unusual, the cysts occurring mainly in the subacute and chronic forms and being sparse, few in number, and randomly distributed (Figure 10).(29) The presence of cysts in association with classic CT findings of $\mathrm{HP}$, such as centrilobular ground-glass nodules and areas of mosaic attenuation, aids in the diagnosis. ${ }^{25,28)}$ It is speculated that airway obstruction, with air trapping and distal airspace dilatation, is responsible for cyst formation in HP.

\section{DESQUAMATIVE INTERSTITIAL PNEUMONIA}

Desquamative interstitial pneumonia (DIP) is characterized by extensive intra-alveolar accumulation of macrophages with anthracotic pigment. Symptoms are nonspecific and include cough and dyspnea. The incidence of DIP in men is twice as high as that in women, being highest around the fifth decade of life. Most patients (> 90\%) are smokers, although DIP is found in other contexts, such as inhalation of inorganic particles and connective tissue diseases, especially rheumatoid arthritis and progressive systemic sclerosis.

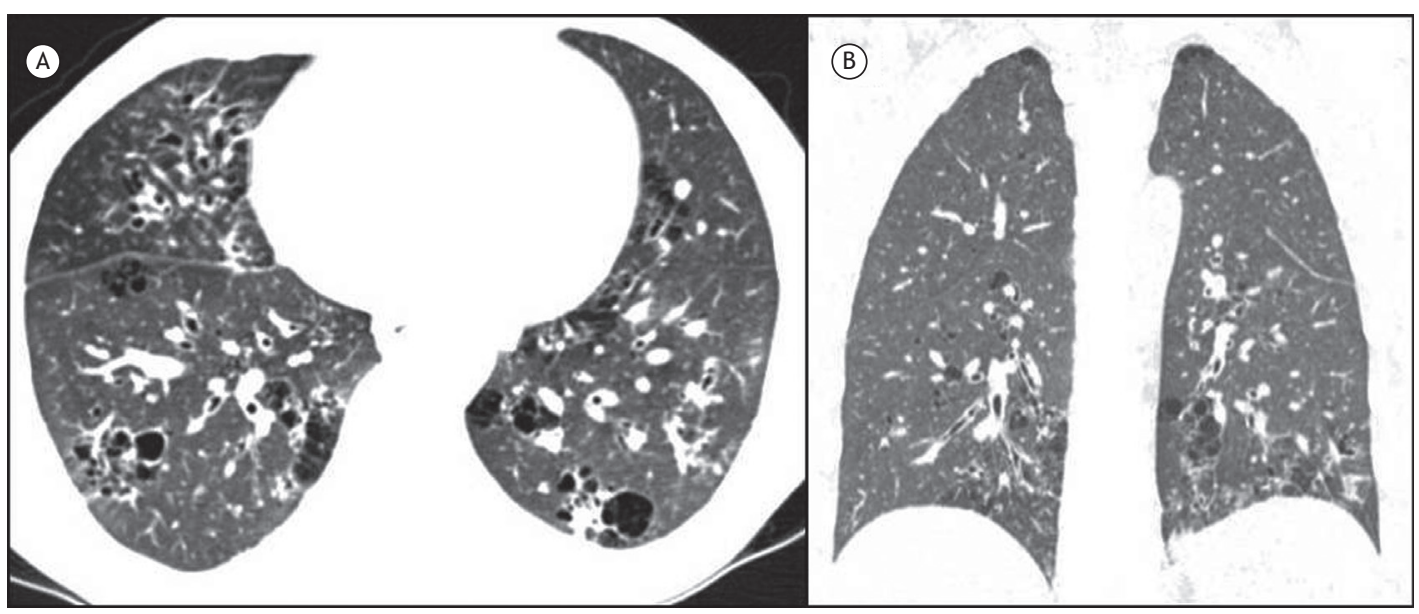

Figure 9. CT scans of a 33-year-old male patient who had been HIV-positive for three years and was poorly compliant with treatment. He had dyspnea and lung involvement secondary to pneumocystosis. In A, axial reconstruction demonstrating diffuse areas of ground-glass density, interspersed with bronchial wall thickening and several peribronchiolar cystic structures of various sizes. In B, coronal reconstruction showing lung cysts with a peribronchiolar distribution. 


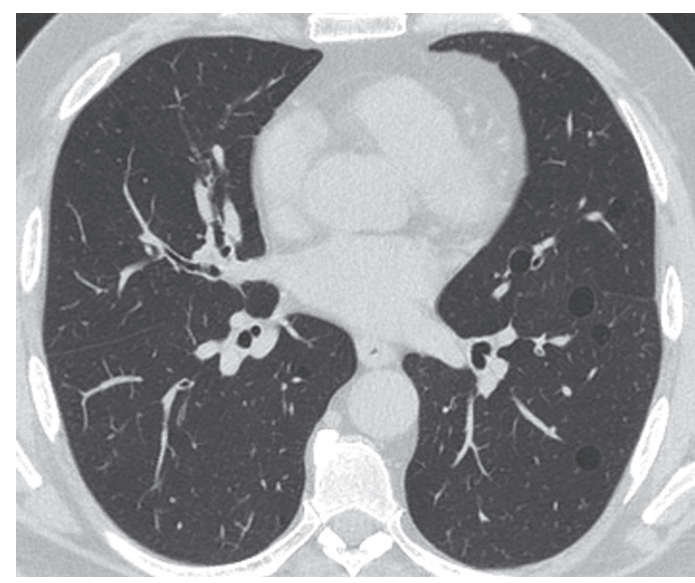

Figure 10. Axial reconstruction of a CT scan of a male patient with a diagnosis of hypersensitivity pneumonitis due to exposure to birds: after the subacute phase, there remained scattered, randomly distributed cysts in the lung parenchyma.

CT findings include small-diameter (up to $2 \mathrm{~cm}$ ), round cysts interspersed with diffuse ground-glass opacities, especially in the lower lobes, usually with mild distortion of the lung architecture (Figure 11).(25,30)

\section{FINAL CONSIDERATIONS}

Many diseases with a variable course, of neoplastic, inflammatory, or infectious origin, can lead to the

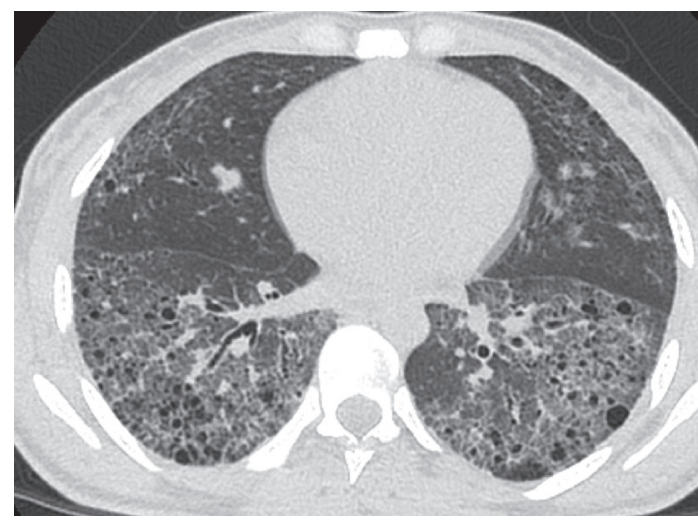

Figure 11. Axial reconstruction of a CT scan of a female patient with limited systemic sclerosis and a desquamative interstitial pneumonitis pattern, which was confirmed by open lung biopsy. The scan shows small-diameter lung cysts interspersed with areas of ground-glass opacity and traction bronchiolectasis, especially in the lower lung fields.

formation of diffuse lung cysts, and other potential etiologies of this radiological pattern have been proposed. HRCT has become an indispensable tool in the analysis of patients with diffuse lung cysts, because the analysis of the characteristics and distribution of the cysts, as well as the identification of other pulmonary and extrapulmonary manifestations, makes it possible to arrive at a definitive diagnosis or to narrow the differential diagnoses, optimizing clinical assessment.

\section{REFERENCES}

1. Silva $\mathrm{Cl}$, Marchiori $\mathrm{E}$, Souza Júnior AS, Müller NL; Comissão de Imagem da Sociedade Brasileira de Pneumologia e Tisiologia. Illustrated Brazilian consensus of terms and fundamental patterns in chest CT scans. J Bras Pneumol. 2010;36(1):99-123. https://doi. org/10.1590/S1806-37132010000100016

2. Gupta N, Vassallo R, Wikenheiser-Brokamp KA, McCormack FX Diffuse Cystic Lung Disease. Part II. Am J Respir Crit Care Med. 2015;192(1):17-29. https://doi.org/10.1164/rccm.201411-2096C

3. Ferreira Francisco FA, Soares Souza A Jr, Zanetti G, Marchiori E. Multiple cystic lung disease. Eur Respir Rev. 2015;24(138):552-64. https://doi.org/10.1183/16000617.0046-2015

4. Costa AN, Marchiori E, Benard G, Araújo MS, Baldi BG, Kairalla $\mathrm{RA}$, et al. Lung cysts in chronic paracoccidioidomycosis. J Bras Pneumol. 2013;39(3):368-72. https://doi.org/10.1590/S180637132013000300015

5. Kawano-Dourado L, Baldi BG, Dias OM, Bernardi FD, Carvalho CR, Dolhnikoff $M$, et al. Scattered lung cysts as the main radiographic finding of constrictive bronchiolitis. Am J Respir Crit Care Med. 2012;186(3):294-5. https://doi.org/10.1164/ajrccm.186.3.294

6. DeMartino E, Go RS, Vassallo R. Langerhans cell histiocytosis and other histiocytic diseases of the lung. Clin Chest Med. 2016;37(3):421-30. https://doi.org/10.1016/J.ccm.2016.04.005

7. McCormack FX, Gupta N, Finlay GR, Young LR, Taveira-DaSilva AM, Glasgow CG, et al. Official American Thoracic Society/ Japanese Respiratory Society Clinical Practice Guidelines: Lymphangioleiomyomatosis Diagnosis and Management. Am J Respir Crit Care Med. 2016;194(6):748-61. https://doi.org/10.1164/ rccm.201607-1384ST

8. Baldi BG, Freitas CS, Araujo MS, Dias OM, Pereira DA, Pimenta SP, et al. Clinical course and characterisation of lymphangioleiomyomatosis in a Brazilian reference centre. Sarcoidosis Vasc Diffuse Lung Dis. 2014;31(2):129-35

9. Xu KF, Feng R, Cui $H$, Tian X, Wang $H$, Zhao J, et al. Diffuse Cystic Lung Diseases: Diagnostic Considerations. Semin Respir Crit Care
Med. 2016;37(3):457-67. https://doi.org/10.1055/s-0036-1580690

10. Panchabhai TS, Farver C, Highland KB. Lymphocytic Interstitia Pneumonia. Clin Chest Med. 2016;37(3):463-74. https://doi. org/10.1016/j.ccm.2016.04.009

11. Guinee DG Jr. Update on nonneoplastic pulmonary lymphoproliferative disorders and related entities. Arch Pathol Lab Med. 2010;134(5):691-701.

12. Toro JR, Pautler SE, Stewart L, Glenn GM, Weinreich M, Toure O, et al. Lung cysts, spontaneous pneumothorax, and genetic associations in 89 families with Birt-Hogg-Dubé syndrome. Am J Respir Crit Care Med. 2007;175(10):1044-53. https://doi.org/10.1164/rccm.200610$14830 \mathrm{C}$

13. Tobino K, Gunji Y, Kurihara M, Kunogi M, Koike K, Tomiyama N, et al. Characteristics of pulmonary cysts in Birt-Hogg-Dubé syndrome: thin-section CT findings of the chest in 12 patients. Eur J Radiol. 2011;77(3):403-9. https://doi.org/10.1016/j.ejrad.2009.09.004

14. Menko FH, van Steensel MA, Giraud S, Friis-Hansen L, Richard S, Ungari $S$, et al. Birt-Hogg-Dubé syndrome: diagnosis and management. Lancet Oncol. 2009;10(12):1199-206. https://doi. org/10.1016/S1470-2045(09)70188-3

15. Colombat M, Stern M, Groussard O, Droz D, Brauner M, Valeyre $\mathrm{D}$, et al. Pulmonary cystic disorder related to light chain deposition disease. Am J Respir Crit Care Med. 2006;173(7):777-80. https://doi. org/10.1164/rccm.200510-1620CR

16. Desai SR, Nicholson AG, Stewart S, Twentyman OM, Flower CD, Hansell DM. Benign pulmonary lymphocytic infiltration and amyloidosis: computed tomographic and pathologic features in three cases. J Thorac Imaging. 1997;12(3):215-20. https://doi. org/10.1097/00005382-199707000-00009

17. Jeong YJ, Lee KS, Chung MP, Han J, Chung MJ, Kim Kl, et al Amyloidosis and lymphoproliferative disease in Sjögren syndrome: thin-section computed tomography findings and histopathologic comparisons. J Comput Assist Tomogr 2004;28(6):776-81. https:// doi.org/10.1097/00004728-200411000-00008 
18. Dodd GD, Boyle JJ. Excavating pulmonary metastases. Am J Roentgenol Radium Ther Nucl Med. 1961;85:277-93.

19. Chaudhuri MR. Cavitary pulmonary metastases. Thorax 1970;25(3):375-81. https://doi.org/10.1136/thx.25.3.375

20. Seo JB, Im JG, Goo JM, Chung MJ, Kim MY. Atypical pulmonary metastases: spectrum of radiologic findings. Radiographics. 2001;21(2):403-17. https://doi.org/10.1148/ radiographics.21.2.g01mr17403

21. Queiroz-Telles F, Escuissato DL. Pulmonary paracoccidioidomycosis. Semin Respir Crit Care Med. 2011;32(6):764-74. https://doi. org/10.1055/s-0031-1295724

22. Barreto MM, Marchiori E, Amorim VB, Zanetti G, Takayassu TC Escuissato DL, et al. Thoracic paracoccidioidomycosis: radiographic and CT findings. Radiographics. 2012;32(1):71-84. https://doi. org/10.1148/rg.321115052

23. Gilroy SA, Bennett NJ. Pneumocystis pneumonia. Semin Respir Crit Care Med. 2011;32(6):775-82. https://doi. org/10.1055/s-0031-1295725

24. Hardak E, Brook O, Yigla M. Radiological features of Pneumocystis jirovecii pneumonia in immunocompromised patients with and without AIDS. Lung. 2010;188(2):159-63. https://doi.org/10.1007/ s00408-009-9214-y

25. Gupta N, Vassallo R, Wikenheiser-Brokamp KA, McCormack FX. Diffuse Cystic Lung Disease. Part I. Am J Respir Crit Care Med. 2015;191(12):1354-66. https://doi.org/10.1164/rccm.201411-2094Cl

26. Quigley MJ, Fraser RS. Pulmonary pneumatocele: pathology and pathogenesis. AJR Am J Roentgenol. 1988;150(6):1275-7. https:// doi.org/10.2214/ajr.150.6.1275

27. Barker AF, Bergeron A, Rom WN, Hertz MI. Obliterative bronchiolitis. N Engl J Med. 2014;370(19):1820-8. https://doi.org/10.1056/ NEJMra1204664

28. Morell F, Villar A, Ojanguren I, Mu-oz X, Cruz MJ. Hypersensitivity Pneumonitis: Challenges in Diagnosis and Management, Avoiding Surgical Lung Biopsy. Semin Respir Crit Care Med. 2016;37(3):395405. https://doi.org/10.1055/s-0036-1580692

29. Franquet T, Hansell DM, Senbanjo T, Remy-Jardin M, Müller NL. Lung cysts in subacute hypersensitivity pneumonitis. J Comput Assist Tomogr. 2003;27(4):475-8. https://doi.org/10.1097/00004728200307000-00003

30. Akira M, Yamamoto S, Hara H, Sakatani M, Ueda E. Serial computed tomographic evaluation in desquamative interstitial pneumonia. Thorax. 1997;52(4):333-7. https://doi.org/10.1136/thx.52.4.333 